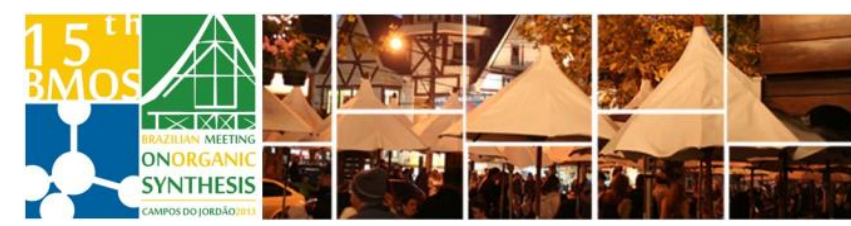

\title{
Synthesis of meso-tetra-(5-iodo-thien-2-yl)-porphyrin; an intermediate for cross-coupling reactions
}

\author{
Maria C. Donatoni, Ygor W. Vieira, Timothy J. Brocksom and Kleber T. de Oliveira* \\ Universidade Federal de São Carlos - UFSCar, Departamento de Química,13565-905, São Carlos, SP, \\ Brazil.
}

*e-mail: kleber.oliveira@ufscar.br; www.lqbo.ufscar.br

Keywords: meso-porphyrins, Heck-Mizoroki reactions, Sonogashira reactions.

\section{INTRODUCTION}

The synthesis of new porphyrins has become a major challenge, mainly due to their wide range of applications, including photochemical cells and photodynamic therapy (PDT). ${ }^{1}$ With the advent of one-pot processes ${ }^{2,3}$ for the synthesis of meso substituted porphyrins, the number of these compounds has increased considerably. Porphyrins with meso-thienyl groups can also be used as building blocks for new porphyrins. One way to functionalize these compounds is the Heck-Mizoroki and Sonogashira cross coupling reactions. ${ }^{4}$ We now propose the synthesis of meso-thien-2-yl-porphyrins functionalized with iodine, ready for cross-coupling reactions.

\section{RESULTS AND DISCUSSION}

lodination of the known thiophene-2-carbaldehyde 1 with iodine in the presence of periodate gave the 5isomer $2(85 \%)$ after crystallization. ${ }^{5}$

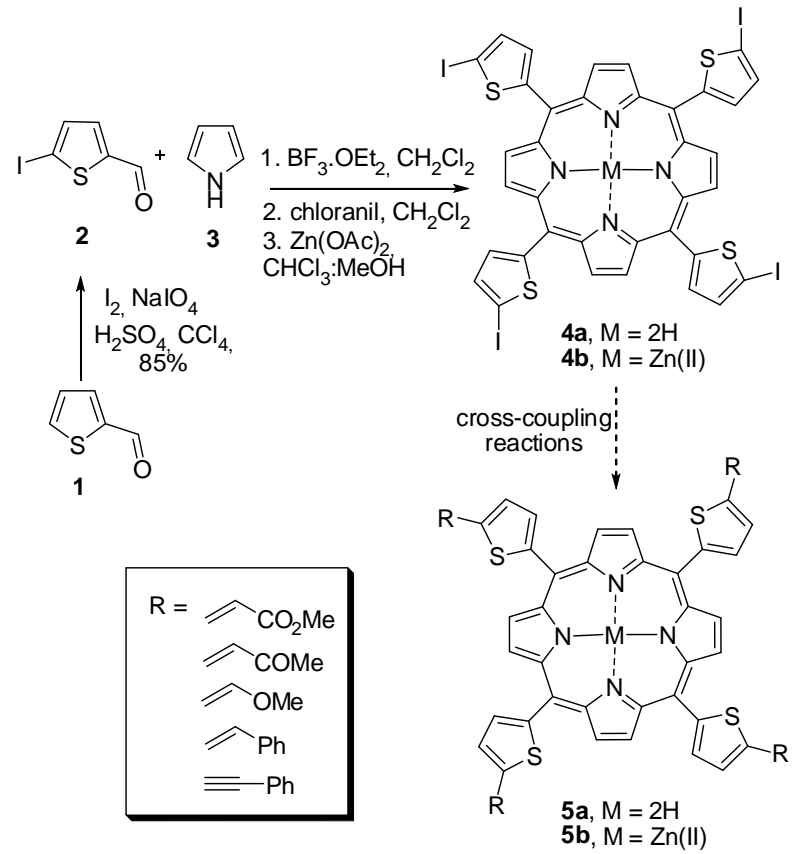

Scheme 1: Synthesis of meso-tetra-iodothien-2-ylporphyrins 3 and 4 .
The compound 2 was tetramerized with pyrrole (3) using $\mathrm{BF}_{3} . \mathrm{OEt}_{2}$, followed by oxidation with chloranil, thus furnishing the porphyrin $4 a$ (Scheme 1). These conditions were shown to be more efficient, with a $20 \%$ yield, than conventional treatment with propionic acid in $12 \%$. Porphyrin 4 a was metallated using $\mathrm{Zn}(\mathrm{OAc})_{2}$ in a $\mathrm{CHCl}_{3}: \mathrm{MeOH}$ (1:1) solution, thereby obtaining the desired porphyrin $\mathbf{4 b}$ in $90 \%$ yield. Presently, we are studying some cross coupling reactions between the porphyrins $4 a$ and $\mathbf{4 b}$ and alkenes and alkynes in order to produce new functionalized thienyl-porphyrin derivatives such as $5 a$ and $5 b$.

\section{CONCLUSION}

We have demonstrated the synthesis of a new meso-tetra-iodo-thien-2-yl-porphyrin, and thus the possibility of further functionalizations via crosscoupling reactions.

\section{ACKNOWLEDGEMENTS}

The authors thank FAPESP (grant numbers 2011/13993-2, 2013/06532-4), CNPq and CAPES for financial support and fellowships.

\section{REFERENCES}

Horn, S.; Dahms, K.; Senge, M. O.; J. Porphyrins Phthalocyanines 2008, 12, 1053.

2. Lindsey, J. S.; Kadish, K. M.; Smith, K. M.; Guilard, R. In The Porphyrin Handbook, Vol. 1; Eds. Academic Press: San Diego, $2000,45$.

3. Prasath, R., Bhavana, P. J. Het. Chem. 2012, 49, 1044.

4. Murray, P. M.; Bower, J. F.; Cox, D. K.; Galbraith, E. K.; Parker,

J. S.; Sweeney, J. B. Org. Process Res. Dev. 2013, 17, 397.

5. Davis, M. C.; Baldwin, L.C.; Groshens, T. J. Tetrahedron Lett. 2012, 53, 1564. 